\title{
Aligned Monotectic Growth in Unidirectionally Solidified Zn-Bi Alloys
}

\author{
B. MAJUMDAR and K. CHATTOPADHYAY
}

The solidification morphology of the $\mathrm{Zn}$-Bi monotectic alloy is studied through directional solidification processing. It is shown that the aligned growth depends on the crystallography of the solid-liquid interface. The best alignment of the monotectic liquid phase $\left(L_{2}\right)$ occurs when the growth direction is $[0001]_{\mathrm{Zn}}$ followed by that of $[10 \overline{1} 0]_{\mathrm{Zn}}$. Aligned growth could not be observed in other growth directions. A parametric approach is adopted, which incorporates the mechanical stability of the three phases at the growing interface and Derby and Favier's criterion for monotectic growth, derived from Jackson and Hunt theory of coupled growth, to identify the possible window of growth conditions and phase spacings where aligned growth is possible.

\section{INTRODUCTION}

MICROSTRUCTURAL developments in monotectic alloys have been extensively studied over the last 20 years. ${ }^{[1-7]}$ It is generally agreed that their behavior is similar to that of eutectic growth, and the classical theory of coupled growth by Jackson and Hunt ${ }^{[8]}$ adequately predicts their microstructural development. ${ }^{[3,5,7]}$ In general, the aspects of the crystallographic anisotropy of the growing solid phase and the resultant changes in the growth conditions are ignored in these reports. Further, the growth of two coupled phases into the melt also requires the establishment of a mechanical equilibrium at the triple junction of the interface. This is not explicitly treated in most of the theoretical developments dealing with coupled growth. Magnin and Trivedi ${ }^{[9]}$ have introduced this criterion in order to explain the spacing selection in eutectic alloys within the framework of the classical eutectic growth theory.

For the case of isotropic surface energy, a stable threephase configuration requires that the second liquid partially wets the growing solid. ${ }^{[10]}$ As pointed out by Cahn, ${ }^{[11]}$ even if the second liquid does not wet the solid-liquid growth interface, it is still possible to have coupled growth at a higher growth velocity. This happens when the pressure that repels the second liquid from the growing solid-liquid interface (known as disjoining pressure) is overcome by the growing interface at a critical growth velocity. Once the three-phase contact is established, the final growth behavior is dictated only by the coupled mass transfer across the interface.

The situation can be different for the case of an anisotropic solid like Zn. Even if the surface energies of the second liquid and solid-liquid interface satisfy a nonwetting condition, the crystallography can play an important role once the disjoining pressure is overcome and the second liquid is in contact with the growing solid. The liquid, in this case, will spread toward the planes having lower surface energies in the solid, thereby developing a crystallographic constraint

B. MAJUMDAR, Scientist, is with the Institute fuer Werkstoffkunde and Werkstofftechnik, Technical University of Clausthal, 38678 Clausthal Zellerfeld, Germany. K. CHATTOPADHYAY, Professor, is with the Department of Metallurgy, Indian Institute of Science, Bangalore 560-012, India. Manuscript submitted June 2, 1998. to the growth process. The goal of this article is to present a detailed experimental study of the microstructural development of a Zn-Bi monotectic alloy under unidirectional solidification conditions and to attempt to test the validity of the current understanding when crystallographic factors are incorporated.

\section{EXPERIMENTAL}

The alloy, with a monotectic composition (Zn-0.6 at. pct $\mathrm{Bi}$ ), was prepared under an argon atmosphere using an induction furnace and was water quenched to obtain a uniform distribution of the two phases. A vertical Bridgman-type setup with a high-temperature gradient capability was used for the unidirectional solidification experiments. Both moving-sample and moving-furnace configurations were used. In order to protect the samples from oxidation, the experiments were carried out in 10-cm-long quartz tubes under an argon atmosphere. Three sets of temperature gradients $(G)$, namely, high (30 to $\left.35 \times 10^{3} \mathrm{~K} / \mathrm{mm}\right)$, medium $\left(20\right.$ to $24 \times 10^{3} \mathrm{~K} /$ $\mathrm{mm}$ ), and low ones (4 to $9 \times 10^{3} \mathrm{~K} / \mathrm{mm}$ ) were used. The growth velocities $(V)$ were varied from 1.1 to $500 \times 10^{-6}$ $\mathrm{m} / \mathrm{s}$. The microstructural examinations were carried out using an optical microscope equipped with a polarized light attachment and a JEOL* JSM840A scanning electron micro-

*JEOL is a trademark of Japan Electron Optics Ltd., Tokyo.

scope. For crystallographic information, transmission electron microscopy was carried out on electron-transparent transverse sections of the specimens using a JEOL*2000FX II microscope. A Gatan ion mill was used for thinning the specimens.

\section{EXPERIMENTAL RESULTS}

The microstructures of unidirectionally solidified samples exhibit a variety of morphologies, depending on the growth velocities and temperature gradients. These are summarized in Table I.

Briefly, at a low-temperature gradient and high growth rate, one observes a random dispersion of $\mathrm{Bi}$, with a bimodal distribution consisting of a coarse and a fine particle-size distribution (Figure 1(a)). The coalescence of the liquid particles at the growth interface is the most probable origin of 
Table I. Summary of the Results for Zn-Bi Alloy

\begin{tabular}{|c|c|c|c|c|c|c|}
\hline \multirow{2}{*}{$\begin{array}{c}\text { Temperature } \\
\text { Gradient } \\
G\left(\times 10^{3} \mathrm{~K} / \mathrm{m}\right)\end{array}$} & \multicolumn{6}{|c|}{ Growth Velocity, $V\left(\times 10^{-6} \mathrm{~m} / \mathrm{s}\right)$} \\
\hline & 1 & 3 & 8 & 17 & 25 to 40 & 100 to 500 \\
\hline High $G(30$ to 35$)$ & $\mathrm{P}, \mathrm{A}, \mathrm{B}$ & $\mathrm{P}, \mathrm{A}, \mathrm{B}$ & $\mathrm{P}, \mathrm{A}, \mathrm{B}$ & $\mathrm{P}, \mathrm{A}, \mathrm{B}$ & $\mathrm{A}$ & $\mathrm{C}, \mathrm{R}$ \\
\hline Medium $G(20$ to 24$)$ & - & $\mathrm{P}, \mathrm{A}, \mathrm{B}$ & $\mathrm{A}, \mathrm{CR}$ & $\mathrm{A}, \mathrm{CR}$ & $\mathrm{A}, \mathrm{CR}$ & - \\
\hline Low $G$ (4 to 9$)$ & - & $\mathrm{C}, \mathrm{R}$ & $\mathrm{C}, \mathrm{R}$ & $\mathrm{C}, \mathrm{D}, \mathrm{R}$ & $\mathrm{D}, \mathrm{R}$ & $\mathrm{D}, \mathrm{R}$ \\
\hline
\end{tabular}

$\mathrm{A}$-aligned droplet, $\mathrm{B}-\mathrm{Bi}$ free band perpendicular to growth direction, $\mathrm{C}-$ cellular, $\mathrm{CR}$-curved rod, $\mathrm{D}$ - dendrite, $\mathrm{P}-$ planar interface, and $\mathrm{R}$-random dispersion.

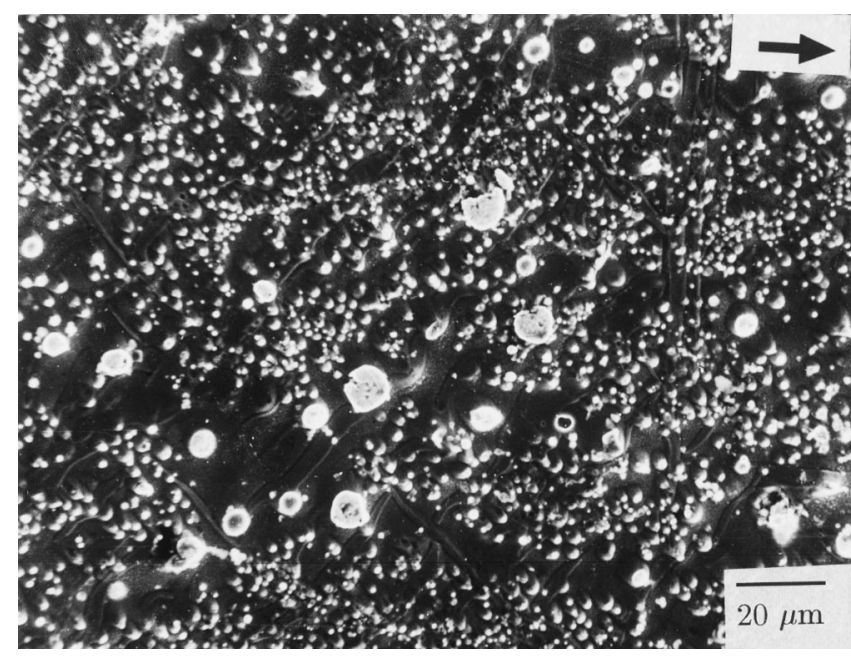

(a)

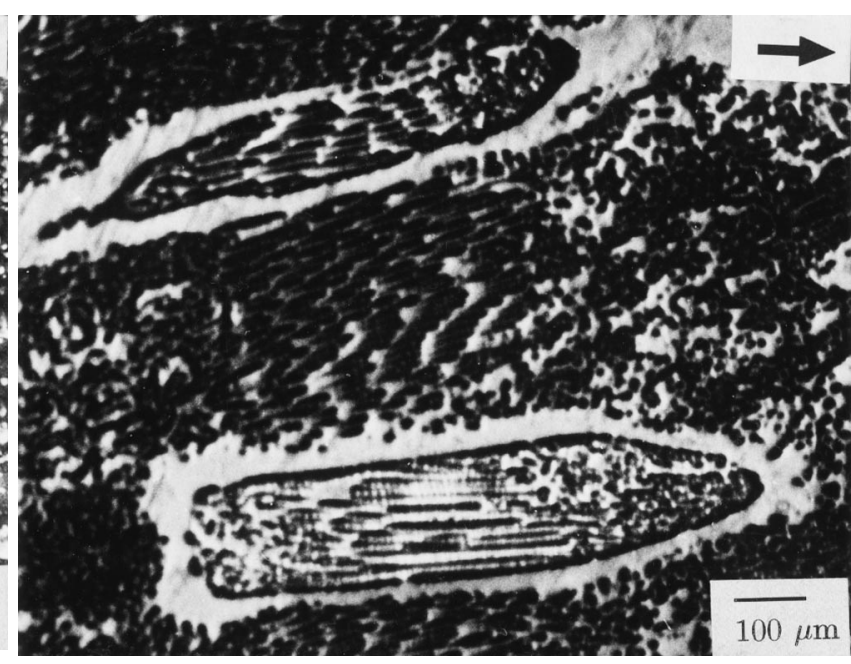

(b)

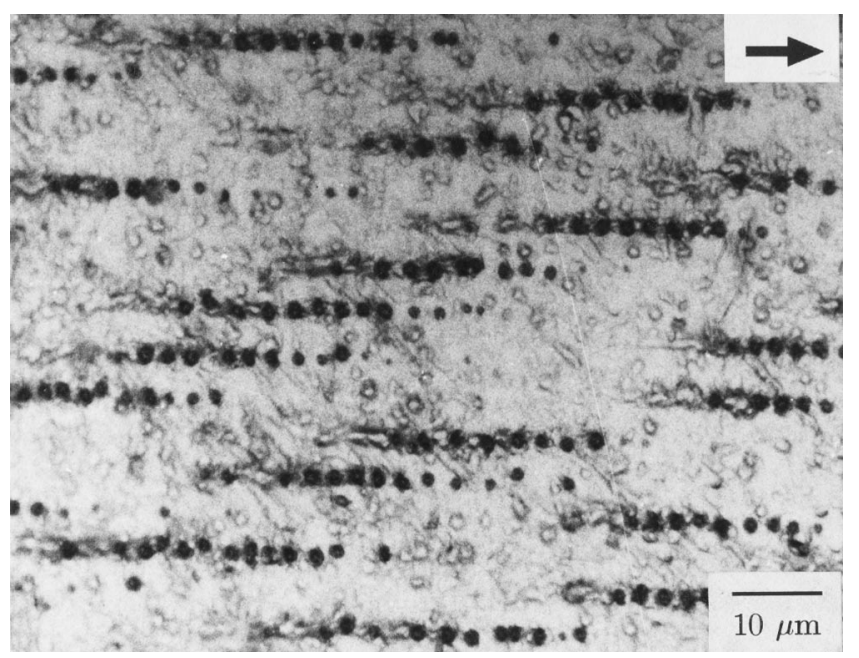

(c)

Fig. 1-Longitudinally sectioned micrographs of Zn-Bi monotectic alloy for different growth conditions with increasing order of temperature gradi ent along growth direction. (a) $G=7 \times 10^{3} \mathrm{~K} / \mathrm{m}$ and $V=500 \times 10^{-6} \mathrm{~m} / \mathrm{s}$ showing the bimodular distribution of Bi droplets dispersed randomly in Zn matrix. (b) $G=22 \times 10^{3} \mathrm{~K} / \mathrm{m}$ and $V=8 \times 10^{-6} \mathrm{~m} / \mathrm{s}$, showing complex microstructure. The aligned droplet arrays are confined within the cells. $(c) G=30 \times 10^{3}$ $\mathrm{K} / \mathrm{m}$ and $V=8 \times 10^{-6} \mathrm{~m} / \mathrm{s}$, revealing aligned rod morphology.

the coarser particles. At medium-temperature gradients, the microstructure indicates unstable growth, with complexities increasing with higher growth rates. A typical complex microstructure is shown in Figure 1(b). At a high-temperature gradient, many of the grains show aligned monotectic growth. This article primarily deals with the latter type of growth (Figure 1(c)). Further results will be presented only to elucidate the nature of this coupled growth.
Figure 2(a) depicts columnar grains grown parallel along the growth direction at a rate of $17 \times 10^{-6} \mathrm{~m} / \mathrm{s}$, with a temperature gradient of $30 \times 10^{3} \mathrm{~K} / \mathrm{m}$. The central grain shows a well-aligned morphology, while the adjacent grains show cellular morphologies containing more-randomly arranged shorter Bi droplets. The latter morphology is similar to that of the eutectic cells and can be termed as monotectic cells. The aligned rods at high magnifications reveal closely 


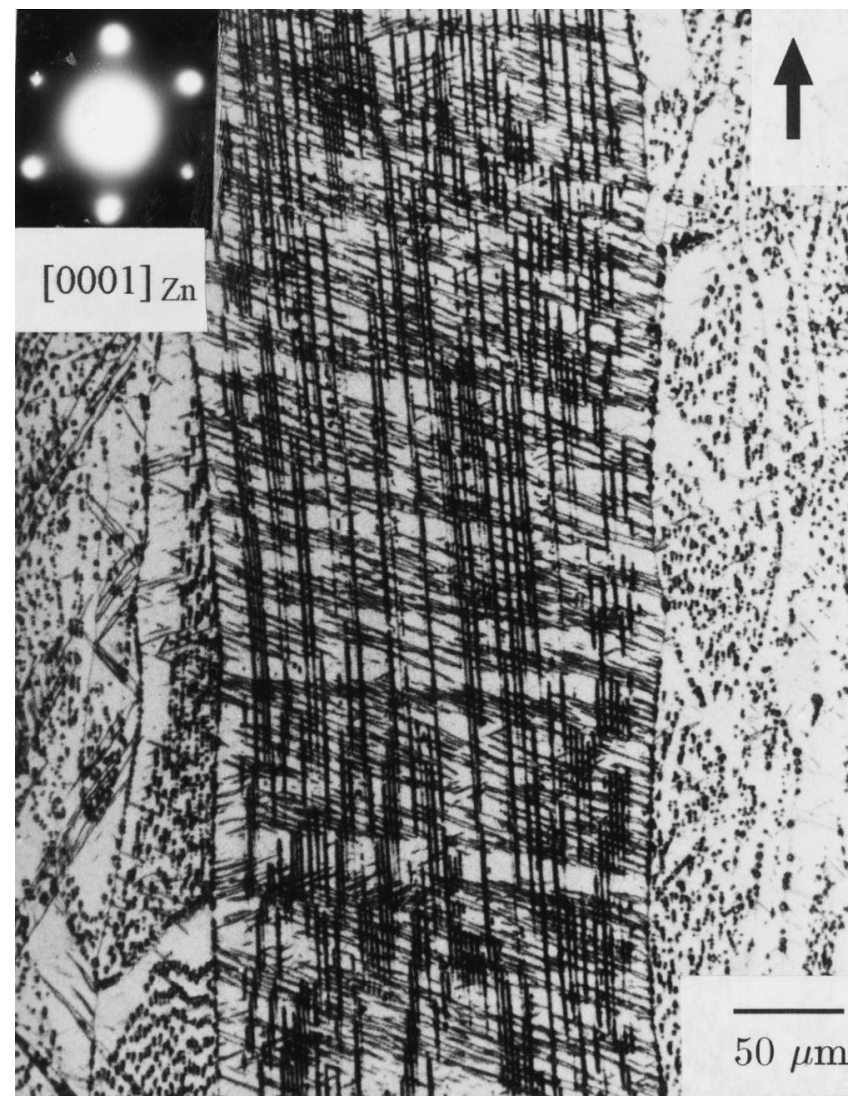

(a)

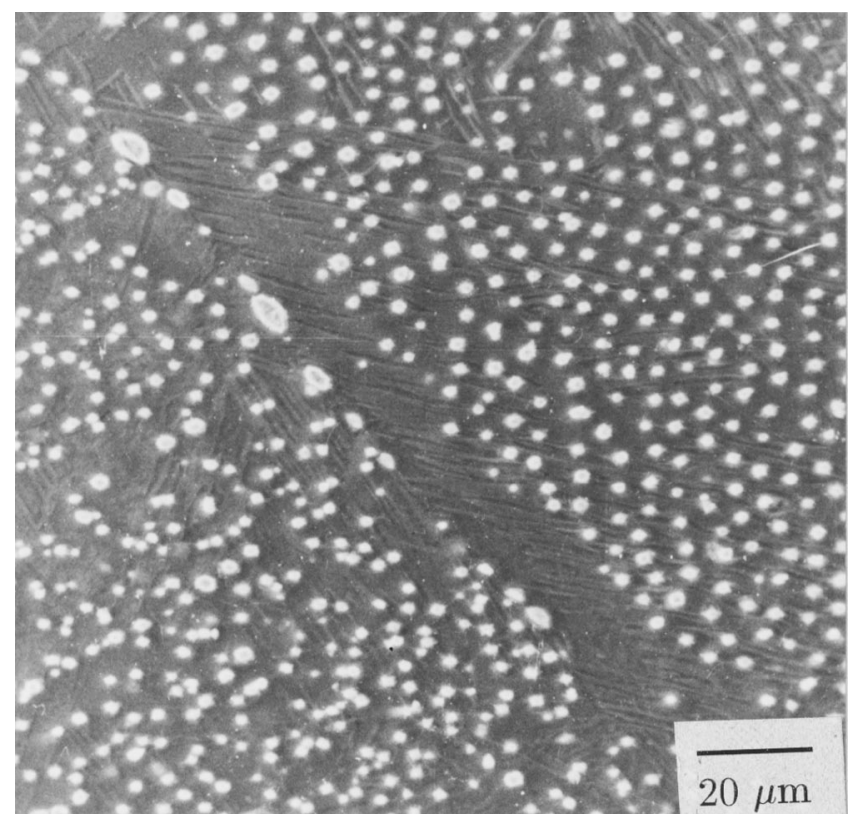

(b)

Fig. 2-(a) Microstructure of $\mathrm{Zn}-0.6$ at. pet Bi alloy grown at a temperauture gradient of $30 \times 10^{3} \mathrm{~K} / \mathrm{m}$ and velocity of $17 \times 10^{-6} \mathrm{~m} / \mathrm{s}$. (a) Longitudinal section showing two columnar grains of different morphology. The central grain corresponds to the perfectly aligned morphology, whereas the other grain shows monotectic cells. The selected area diffraction pattern from the aligned grain at zero tilt reveals [0001] zone axis (inset). (b) Transverse section showing the same two grains. spaced rows of droplets. The condition of breakdown of the liquid rods to such a droplet array is discussed elsewhere. ${ }^{[12]}$ A cross-sectional microstructure of the boundary regions between the perfectly aligned and less-perfectly aligned grains is shown in Figure 2(b). The selected-area diffraction pattern at a zero-tilt condition from the transverse cut of the central grain reveals a [0001] zone-axis pattern of $\mathrm{Zn}$ (inset, Figure 2(a)). A careful experiment indicates the exact zone axis to be 4 deg away from the zero-tilt condition. Considering the possibility of error during slicing and thinning, one can conclude that the aligned growth direction is $[0001]_{\mathrm{Zn}}$.

Although a $[0001]_{Z n}$ growth direction yields the mostperfectly aligned monotectic growth of liquid $\mathrm{Bi}$ and solid $\mathrm{Zn}$, reasonable aligned growth could be observed in a $[10 \overline{1} 0]_{\mathrm{Zn}}$-growth-direction microstructure. In Figure 3 , the authors have presented a typical example. The growth conditions used in this experiment are $G=30 \times 10^{3} \mathrm{~K} / \mathrm{m}$ and $V=8 \times 10^{-6} \mathrm{~m} / \mathrm{s}$. The sample consists of two long grains (Figure 3(a)). Observation of the longitudinal section at the optical microscope level indicates that one of the grains has an aligned morphology, while the other grain exhibits a microstructure consisting of poorly aligned Bi droplets. The grains have $[10 \overline{1} 0]_{\mathrm{Zn}}$ and $[1 \overline{2} 1 \overline{3}]_{\mathrm{Zn}}$ growth directions respectively.

It is not necessary that well-developed aligned growth always remains parallel to the heat-transfer direction. This can be clearly seen at the higher growth rate, when the crystallographic influence becomes dominant. Figure 4 shows an example. However, in such cases, the rod/arrayed droplets are not strictly linear and often show irregular features indicating unstable growth.

The inter-rod spacings of the aligned growth were measured at each growth rate for the high-temperature-gradient condition. This is shown in Figure 5.

\section{DISCUSSION}

\section{A. Surface-Energy Anisotropy and Nucleation of $L_{2}$}

In order to develop a coupled-growth morphology during solidification, a three-phase contact at the solid-liquid interface involving two liquid phases $\left(L_{1}\right.$ and $\left.L_{2}\right)$ and a solid phase $(S)$ is necessary. The second liquid phase, $L_{2}$, is formed from $L_{1}$ by a nucleation process. The growing solid phase can provide the nucleation site, resulting in a three-phase contact. The necessary conditions for this, which requires a stable three-phase contact have been discussed by Chadwick. ${ }^{[10]}$ Figure 6 shows the schematic illustration of the situation. Following Chadwick, the surface-energy balance requirement gives the following conditions:

$$
\gamma_{s-l_{2}} \leq \gamma_{s-l_{1}}+\gamma_{l_{1}-l_{2}}
$$

and

$$
\gamma_{s-l_{1}} \leq \gamma_{s-l_{2}}+\gamma_{l_{1}-l_{2}}
$$

Here $\gamma_{s l_{1}}, \gamma_{s l_{2}}$, and $\gamma_{l_{1} l_{2}}$ are the surface energies of the $S-L_{1}$, $S-L_{2}$, and $L_{1}-L_{2}$ interfaces, respectively. In case the solid exhibits strong anisotropy of the surface energy, the equation needs to be evaluated for each surface in contact with the liquid. Experimentally, for anisotropic materials, it is often 


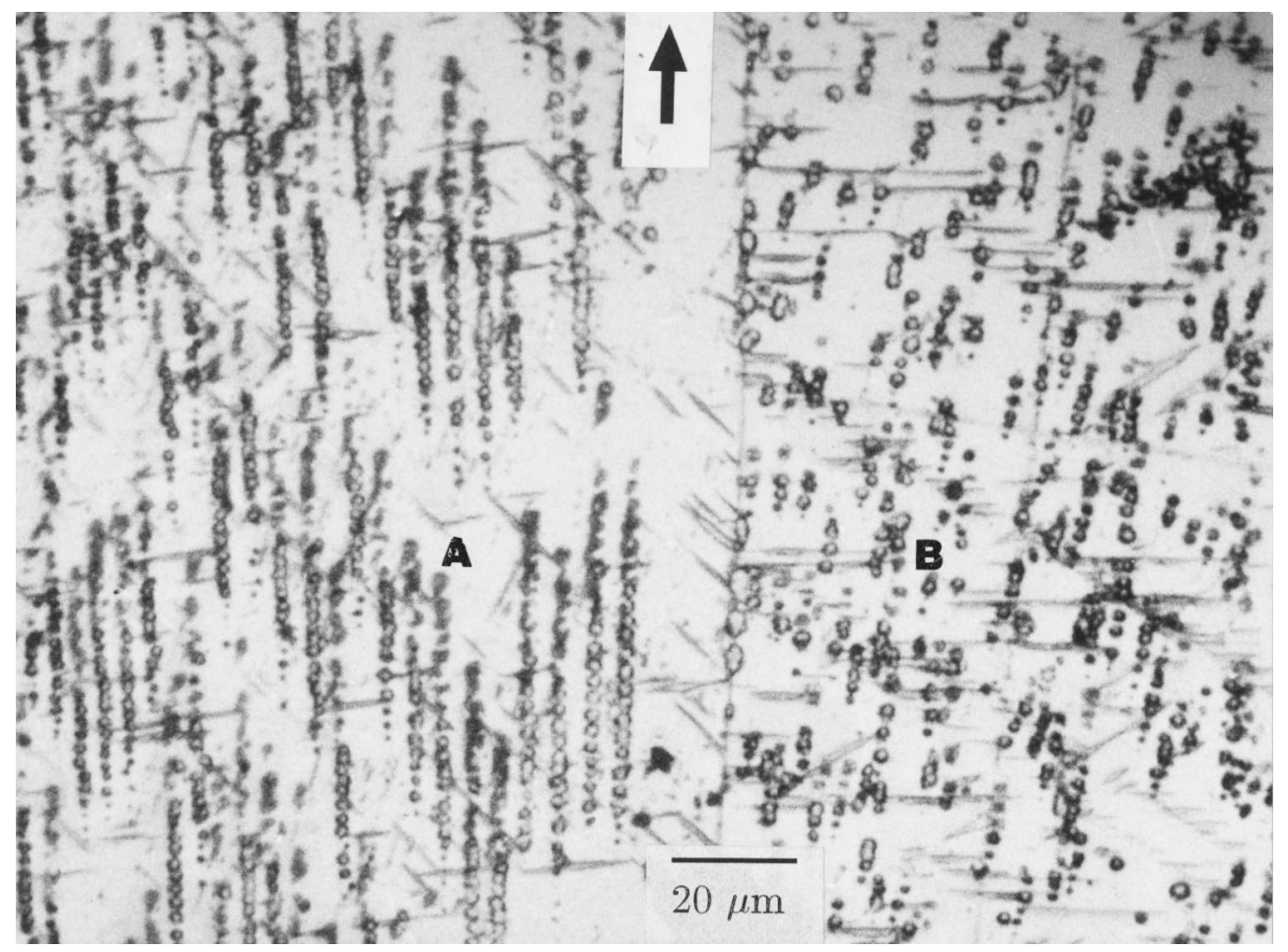

(a)

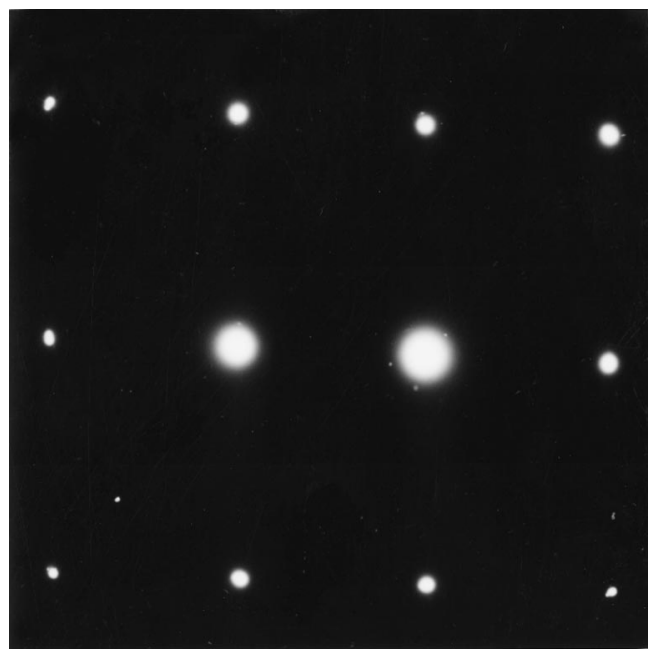

(b)

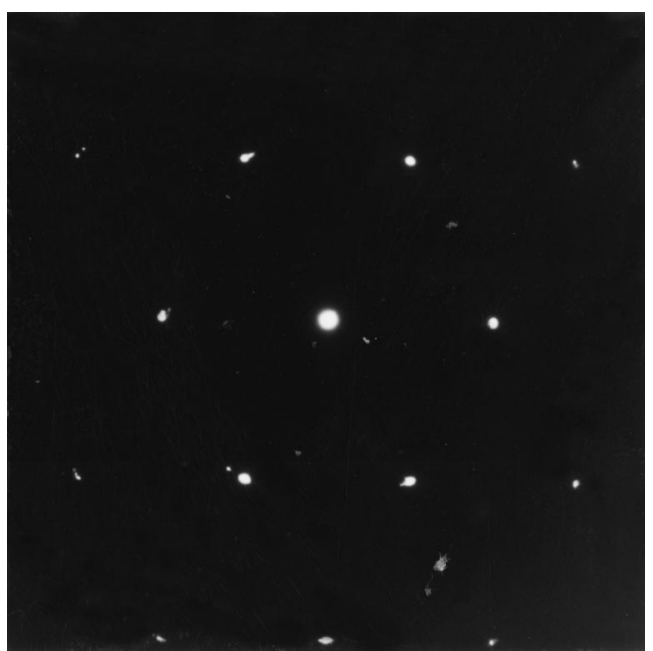

(c)

Fig. 3-Microstructures of a directionally solidified Zn- 0.6 at. pct Bi alloy grown with a temperature gradient of $30 \times 10^{3} \mathrm{~K} / \mathrm{m}$ and growth velocity of 8 $\times 10^{-6} \mathrm{~m} / \mathrm{s}$. The growth direction is indicated by the arrow. (a) Optical micrograph showing two parallel grains: one with aligned morphology (marked as A), and the other (marked as B) with a somewhat random droplets morphology. Electron diffraction patterns at zero tilt condition taken from the transverse cut of grains marked A and $\mathrm{B}$ reveal $(b)[10 \overline{1} 0]_{\mathrm{Zn}}$ and $(c)[1 \overline{2} 13]_{\mathrm{Zn}}$ zone axes, respectively.

easier to determine the surface-energy ratios (rather than the absolute surface energies of each plane) of the different planes ${ }^{[13]}$ from the equilibrium shape. This is known as the anisotropy ratio $(K)$ and, for the isotropic case, it attains a value of 1 . For hexagonal materials, one can define the anisotropy ratio for any $\{h k i l\}$ plane as

$$
K_{h k i l-L_{i}}=\frac{\gamma_{h k i l-L_{i}}}{\gamma_{0001-L_{i}}}
$$

Substituting Eq. [2] in [1a] and rearranging, one gets

$$
\begin{gathered}
\left(\frac{K_{h k i l-L_{1}}}{K_{h k i l-L_{2}}}\right) \cdot\left(\frac{\gamma_{0001-L_{1}}}{\gamma_{0001-L_{2}}}\right)+\left(\frac{1}{K_{h k i l-L_{2}}}\right) \\
\cdot\left(\frac{\gamma_{l_{1}-l_{2}}}{\gamma_{0001-L_{2}}}\right) \geq 1
\end{gathered}
$$

Therefore, the condition for the stable three-phase contact 


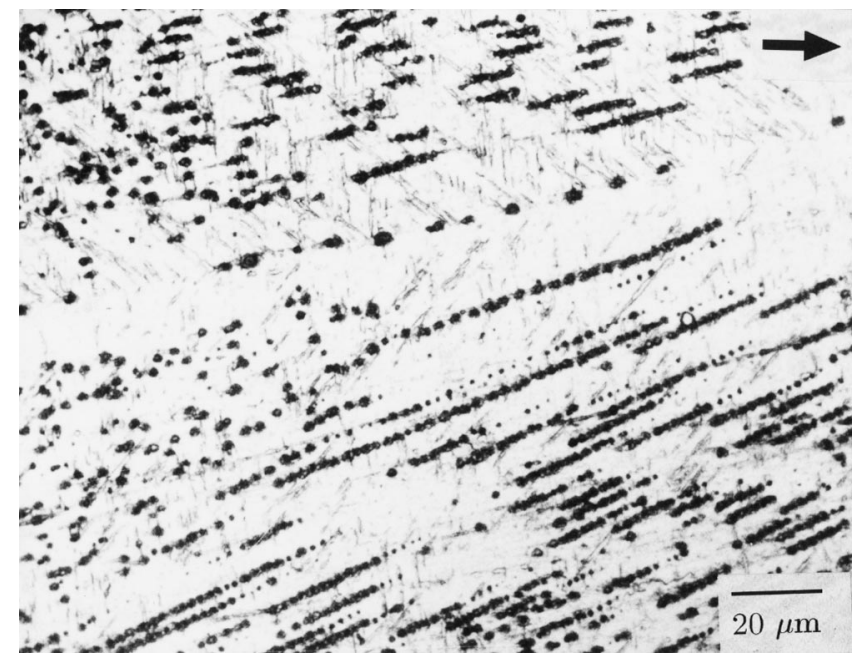

Fig. 4-Microstructures of the longitudinal section of the unidirectionally solidified alloys showing deviation of aligned growth direction from the heat-transfer direction. Growth conditions are $V=3 \times 10^{-6} \mathrm{~m} / \mathrm{s}$ and $G=$ $30 \times 10^{3} \mathrm{~K} / \mathrm{m}$.

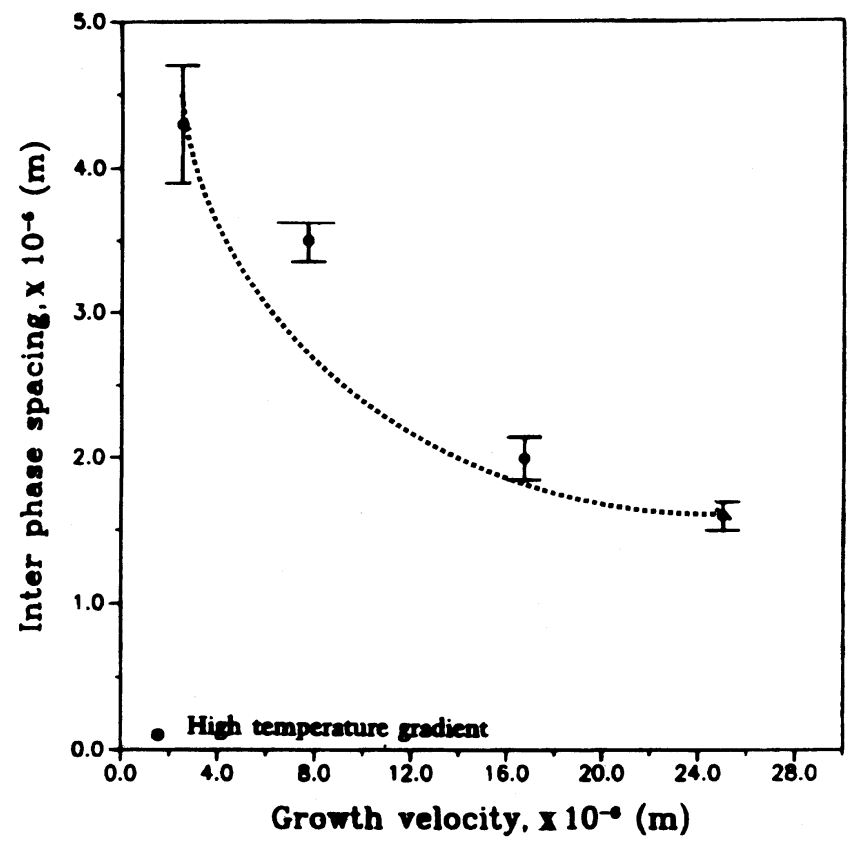

Fig. 5-Variation of interphase spacing as a function of growth velocity at high-temperature gradient condition in $\mathrm{Zn}-0.6$ at. pct alloy.

at any arbitrary interface $\{h k i l\}$ plane can be determined from the value of the function $F$, given by

$$
F=K_{c} \cdot A+\left(\frac{1}{K_{h k i l-L_{2}}}\right) \cdot B
$$

where $A$ and $B$ are the dimensionless surface-energy numbers, defined as the ratio of the surface energy of the 0001 $-L_{1}$ and $L_{1}-L_{2}$ interface with respect to the $0001-L_{2}$ surface energy. The value of $A$ primarily reflects the composition dependence of the surface energy of the liquid-solid interface. The coefficient of $A\left(K_{c}\right)$ represents the composition dependence of the surface-energy anisotropy ratio. For the stable contact, the function should be equal to or greater

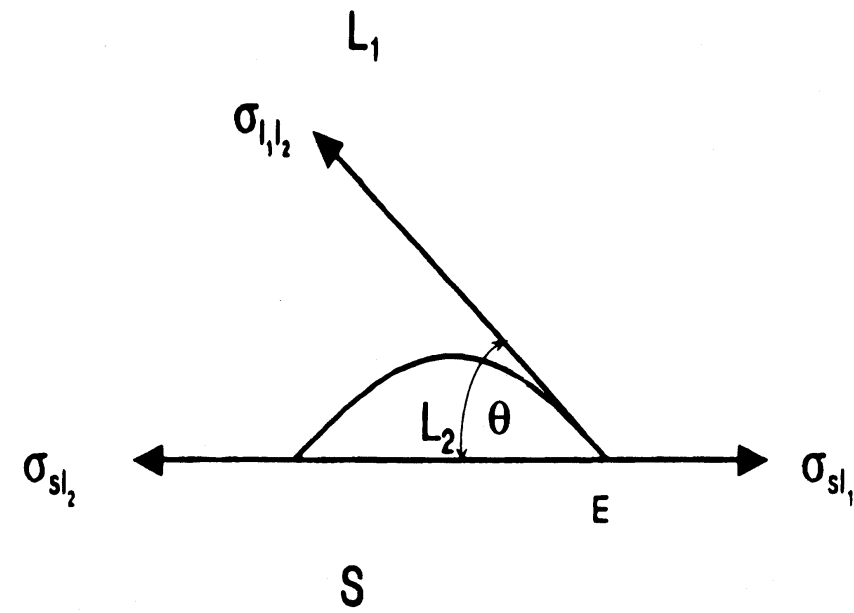

Fig. 6-A schematic representation of three phase contact between the solid $S$, liquid $L_{1}$, and liquid $L_{2}$.

than 1. It is often reasonable to assume that the anisotropy ratio of the surface energies is independent of the liquid composition for a given structure $\left(K_{c}=1\right)$. In that case, the condition for the stable contact is

$$
\left(\frac{\gamma_{l_{1}-l_{2}}}{\gamma_{0001-L_{2}}-\gamma_{0001-L_{1}}}\right) \geq K_{h k i l-L_{2}}
$$

The surface-energy data for the $\mathrm{Zn}$-Bi system at a monotectic temperature are given in Table II. ${ }^{[5]}$ These data correspond to the basal plane of zinc. ${ }^{[14]}$ Use of these data yields the criterion for the stable three-phase contact at the $(h k i l)_{\mathrm{Zn}}$ plane to be

$$
K_{h k i l-L_{2}} \leq 2
$$

The shape of liquid Bi cavities of nanometric size, dispersed in the $\mathrm{Zn}$ matrix, has recently been studied. ${ }^{[15]}$ The bounding interfaces are the (0001) and $\{10 \overline{1} 0\}$ planes. The small size allows us to assume those to be the equilibrium shape, and, hence, a value of the anisotropy ratio between those two close-packed planes can be obtained. This value turns out to be slightly larger than 2 . The anisotropic ratio for other planes of zinc will be still larger. ${ }^{[16]}$ Therefore, we conclude that, excepting the basal plane, most of the other planes of $\mathrm{Zn}$ have a nonwetting character. The character of the $\{10 \overline{1} 0\}$ planes is marginal and may just be wetted. Thus, $L_{2}$ phase cannot nucleate in contact with other planes. For initiating the coupled growth when these planes face the $S-L_{1}$ interface, the $L_{2}$ phase has to nucleate in the melt and is later trapped by the moving $S-L_{1}$ interface. The crystallography of growth established in the present investigation clearly suggests that, for the $\mathrm{Zn}$-Bi monotectic alloy, the most-stable coupled growth is associated with a (0001) plane of $\mathrm{Zn}$

Table II. Relative Interfacial Energies among the Phases at Monotectic Temperature for $\mathrm{Zn}-\mathrm{Bi}^{[5]}$ (the Energies are for (0001) Plane of $\mathrm{Zn}$ )

\begin{tabular}{lccc}
\hline & $\begin{array}{c}\text { Energy } \\
\text { between } \\
S_{1}-L_{1}\left(\mathrm{~J} / \mathrm{m}^{2}\right)\end{array}$ & $\begin{array}{c}\text { Energy } \\
\text { between } \\
L_{1}-L_{2}\left(\mathrm{~J} / \mathrm{m}^{2}\right)\end{array}$ & $\begin{array}{c}\text { Energy } \\
\text { between } \\
S_{1}-L_{2}\left(\mathrm{~J} / \mathrm{m}^{2}\right)\end{array}$ \\
\hline System & 0.09 & 0.06 & 0.12 \\
\hline
\end{tabular}


facing the liquid and growing normal to it. Clearly, for an anisotropic solid, the requirement of $L_{2}$ nucleation favors a coupled-growth geometry, which provides a stable threephase contact.

\section{B. Coupled Monotectic Growth}

The kinetics of coupled diffusional growth of two phases is modeled by Jackson and Hunt ${ }^{[8]}$ for a eutectic system. Their model has been adopted to monotectic aligned growth by several investigators. ${ }^{[3,5,7]}$ It is generally found that, for monotectic growth, the experimental value of phase spacing $(\lambda)$ and growth velocity satisfies the constancy of $\lambda^{2} V$ within the range of experimental uncertainty. The data obtained in the present experiments are shown in Figure 5. The $\lambda$ vs $V$ plot follows a parabolic behavior. A statistical fit of $\lambda^{2} V$ as a function of $V$ yields a best-fit line nearly parallel to the growth axis (the slope of the line drawn by regression analysis is 0.018$)$. The mean value of $\lambda^{2} V$ turned out to be $5.5 \times$ $10^{-17} \mathrm{~m}^{3} / \mathrm{s}$.

\section{A parametric approach to coupled growth in an anisotropic system}

In the case of anisotropic materials, the surface energies of different planes are not the same, and this will have an influence on the coupled-growth interface. The issue of the stability of a given configuration of planes will have a constraining influence on the interface shape of the coupled growth. Unfortunately, direct visualization of the growth interface, in the case of an anisotropic solid, is not available. We have avoided the interrupted quenching experiments, since it is well known that phases can rapidly reorient during quenching. Such experiments, therefore, instead of providing resolution, create further confusion. Instead, we have adopted a parametric approach to study the coupledgrowth behavior.

We first consider the mechanical stability of the coupledgrowth interface. This requires a surface-tension balance at the three-phase junction along the cylindrical axis of the $L_{2}$ rod in contact with the Zn matrix. The geometry of the situation is different from that shown in Figure 6 and represented schematically in Figure 7. In this figure, the threephase equilibrium exists at the point $E$, where the $S_{1}$ and $S_{2}$ surfaces of the $\mathrm{Zn}$ matrix are equilibrated with the $L_{1}-L_{2}$ interface. The $S_{3}$ surface is the macroscopic-growth interface. Let us consider that the directions of the surface tensions (which are, numerically, the same as the surface energies) $\sigma_{l_{1}-l_{2}}$ and $\sigma_{s_{2}-l_{1}}$ make the angles $\theta_{l}$ and $\theta_{s}$, respectively, with a horizontal axis, which is normal to the $S_{1}$ $L_{2}$ interface.

We now examine the possible cases when a stable triple junction exists for a given $S_{1}$ interface when the $L_{1}-L_{2}$ surface energy $\left(\sigma_{l_{1}-l_{2}}\right)$ is known. From the force balance at point $E$, one can obtain

$$
\sigma_{s_{2}-l_{1}}=\frac{\sigma_{l_{1}-l_{2}} \cos \theta_{l}}{\cos \theta_{s}}
$$

and

$$
\sigma_{s_{1}-l_{2}}=\sigma_{s_{2}-l_{1}} \sin \theta_{s}+\sigma_{l_{1}-l_{2}} \sin \theta_{l}
$$

Combining the previous two equations, we obtain

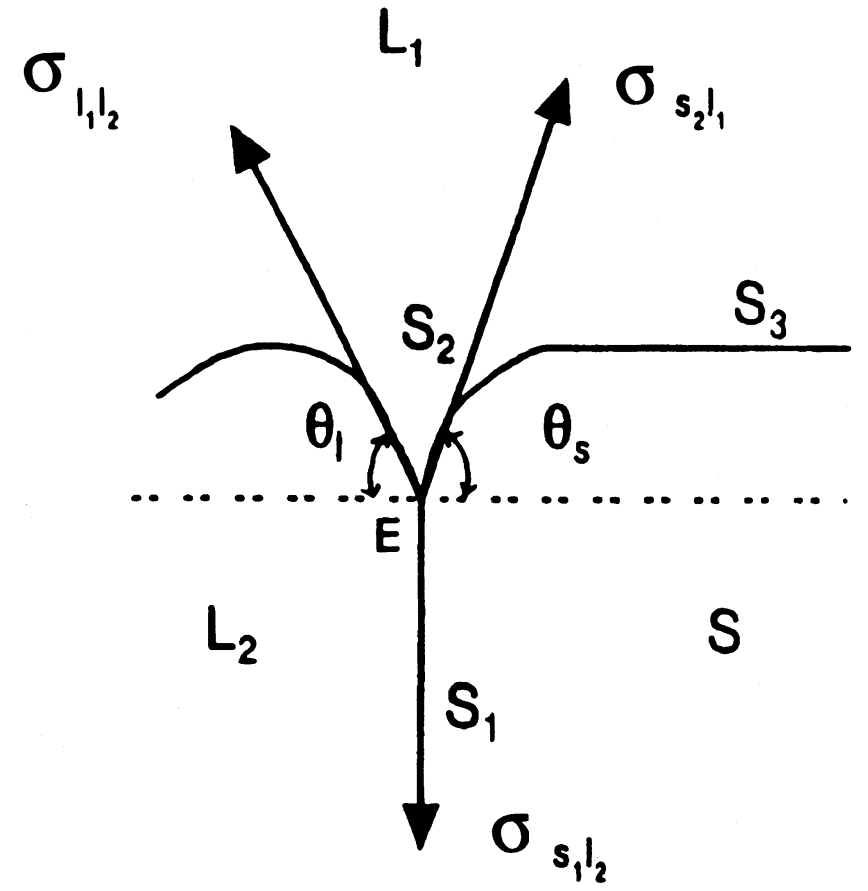

Fig. 7-A schematic representation of the three phase contacts during the cooperative monotectic growth. The figure shows a detailed force balance at the point $E$, where surfaces $S_{1}$ and $S_{2}$ are in mechanical equilibrium with $L_{1}-L_{2}$ interfaces. $S_{3}$ is a growing interface.

$$
\theta_{s}=\tan ^{-1}\left(\frac{\sigma_{s_{1}-l_{2}}}{\sigma_{l_{1}-l_{2}} \cos \theta_{l}}-\tan \theta_{l}\right)
$$

Therefore, for given $\sigma_{l_{1}-l_{2}}$ and $\sigma_{s_{1}-l_{2}}$ surface tensions, one can obtain the combination of $\sigma_{s_{2}-l_{1}}$ and $\theta_{s}$ for each $\theta_{l}$ angle which will satisfy the equilibrium condition. Thus, we get a window for a possible $\theta_{l}, \theta_{s}$, and $\sigma_{s_{2}-l_{1}}$ combination for a stable triple junction.

The basic postulate of the Jackson-Hunt theory ${ }^{[8]}$ is that the shape of the solid-liquid interface is dictated by the requirement of constant undercooling ahead of the two growing solids, and that growth occurs at the extremum. Derby and Favier ${ }^{[5]}$ applied this constant-undercooling requirement to develop a criterion for predicting the stable growth of a coupled monotectic interface in the framework of the Jackson-Hunt theory. The condition obtained for such a growth situation is ${ }^{[5]}$

$$
\frac{\Gamma_{l}}{\Gamma_{s}} \geq \frac{v_{f}\left(4+v_{f}-\left(1-v_{f}\right) \frac{m_{l}}{m_{s}}\right)}{\left(1-v_{f}\right)\left(5-v_{f}\left(1+\frac{m_{l}}{m_{s}}\right)\right)}
$$

Here, $v_{f}$ is the volume fraction of the rod phase. The slopes of the liquidus for $S$ and $L_{2}$ are represented by $m_{s}$ and $m_{l}$, respectively. Although the derivation of the Derby and Favier criterion is undertaken for a nonwetting situation, there exists no restriction for other situations. Thus, the functions $\Gamma_{s}$ and $\Gamma_{l}$ are defined as dimensionless average interfacial energies normalized with the latent heat of transformation times the sine of dihedral angles. These are given by

$$
\Gamma_{l}=\frac{\sigma_{l_{1} l_{2}} \sin \theta_{l}}{L_{l}}
$$


Table III. The Value of the Different Material Parameters for Zn-Bi System

\begin{tabular}{|c|c|c|c|}
\hline & Parameters & Value & References \\
\hline$T_{m}$ & monotectic temperature & $689.0 \mathrm{~K}$ & 20 \\
\hline$C_{m}$ & monotectic composition & 0.006 mole fraction & 20 \\
\hline$L_{l}$ & latent heat of $L_{2}$ & $7.1 \times 10^{8} \mathrm{~J} / \mathrm{m}^{3}$ & 21 \\
\hline$L_{s}$ & latent heat of $S$ & $7.3 \times 10^{8} \mathrm{~J} / \mathrm{m}^{3}$ & 21 \\
\hline$m_{l}$ & liquidus slope of $L_{2}$ & $46.2 \times 10^{2} \mathrm{~K} /$ mole fraction & 20 \\
\hline$m_{s}$ & liquidus slope of $S$ & $5.83 \times 10^{2} \mathrm{~K} /$ mole fraction & 20 \\
\hline$C_{0}$ & total rejected solute & 0.63 mole fraction & 20 \\
\hline$\eta_{\mathrm{Zn}}$ & viscosity of $\mathrm{Zn}$ & $3.85 \times 10^{-3} \mathrm{~J} \mathrm{~s} \mathrm{~m}^{-3}$ & 21 \\
\hline$\eta_{\mathrm{Bi}}$ & viscosity of $\mathrm{Bi}$ & $1.37 \times 10^{-3} \mathrm{~J} \mathrm{~s} \mathrm{~m}^{-3}$ & 21 \\
\hline$a$ & ionic diameter of $\mathrm{Zn}$ & $1.66 \times 10^{-10} \mathrm{~m}$ & 22 \\
\hline$H_{\mathrm{Zn}}$ & enthalpy of mixing & $23 \times 10^{3} \mathrm{~J} / \mathrm{mole}$ & 23 \\
\hline$H_{\mathrm{Bi}}$ & enthalpy of mixing & $14 \times 10^{3} \mathrm{~J} / \mathrm{mole}$ & 23 \\
\hline $\mathrm{k}$ & Boltzmann constant & $1.38 \times 10^{-23} \mathrm{~J} / \mathrm{K}$ & 21 \\
\hline$v_{f}$ & volume fraction of $\mathrm{Bi}$ & 0.017 & 20 \\
\hline$M$ & Bessel function & 0.007 & 8 \\
\hline
\end{tabular}

$$
\Gamma_{s}=\frac{\sigma_{s_{2}-l_{1}} \sin \theta_{s}}{L_{s}}
$$

where $L_{l}$ and $L_{s}$ are the latent heat of transformation of $L_{2}$ and $S$, respectively. For the nonwetting case, $\theta_{l}$ and $\theta_{s}$ will be $90 \mathrm{deg}$. One can estimate the range of $\theta_{l}$ (with corresponding $\theta_{s}$ and $\left.\sigma_{s_{2}-l_{1}}\right)$ values which satisfies both the conditions of equal undercooling and mechanical stability.

It is also possible to estimate the constant in the relation $\lambda^{2} V=C$ for each of these possible configurations which satisfy both the equal-undercooling and mechanical-stability criterion. The constant $C$ is the material characteristic and is defined as ${ }^{[8]}$

$$
\lambda^{2} V=C=\left(\frac{\zeta \frac{\Gamma_{l}}{m_{l}}+\frac{\Gamma_{s}}{m_{s}}}{2 \sqrt{(1+\zeta)} C_{0} M}\right) T_{m} D
$$

where $\zeta=\left(1 / v_{f}-1\right)$. The term $T_{m}$ denotes the monotectic isotherm. The constant $M$ is the Bessel function and is related to the volume fraction of the rod phase. The term $D$ is the interdiffusion coefficient, and $C_{0}$ is the total amount of rejected solute from the interface, which can be obtained from the phase diagram.

\section{Application to the Zn-Bi monotectic growth}

For obtaining stable steady-state growth, it is necessary that the crystallographic constraint that develops due to the anisotropic nature of the $\mathrm{Zn}$ does not restrict the coupled growth. The two lowest-energy interfaces of $\mathrm{Zn}$ with liquid, in decreasing order, are the $\{10 \overline{1} 0\}$ and (0001) plane. ${ }^{[15,16]}$ Thus, the two most-probable configurations are (1) the (0001) plane as a growth interface, with liquid spreading along the $\{10 \overline{1} 0\}$ planes normal to the growth interface, and (2) the $\{10 \overline{1} 0\}$ plane as a growth interface, with the (0001) plane lying perpendicular to the growth interface. This is consistent with the crystallographic nature of the Zn crystal, which has two specific growth axes, [0001] and [1010]. ${ }^{[17]}$ It follows that, for a planar growth, the advancing plane will be either $(0001)$ or $\{10 \overline{1} 0\}$, with liquid $L_{2}$ spreading along the $\{10 \overline{1} 0\}$ and (0001) planes, respectively.

The surface energies for the (0001) plane and the $L_{1}-L_{2}$ interface are given in Table II. For the case of $\{10 \overline{1} 0\}$ planes, it is necessary to multiply the basal-plane value by the anisotropic ratio of the $\{1010\}$ plane. This is very close to 2 when the surface is in contact with the Bi liquid. ${ }^{[14]}$ Table III summarizes all the relevant data necessary for the evaluation of Eqs. [7] through [11]. For the estimation of the Jackson-Hunt constant, the interdiffusion coefficient needs to be known. This can be evaluated from the knowledge of liquid viscosity by using the Stoke-Einstein formula given by ${ }^{[18]}$

$$
D=\frac{\mathrm{k} T_{m} \eta}{3 a}
$$

where $\mathrm{k}$ is the Boltzmann constant, $\eta$ is the viscosity, $T_{m}$ is the melting point, and $a$ is a characteristic distance, taken as the ionic diameter. Because of the very dilute solution, the value of $a$ is taken as that for the pure $\mathrm{Zn}^{+2}$ ion. The viscosity of the alloy is calculated from the formula given by Moelwyn-Hughes ${ }^{[19]}$ using the thermodynamic interaction parameters of the alloy. It is given by

$$
\eta=\left(X_{\mathrm{Zn}} \eta_{\mathrm{Zn}}+X_{\mathrm{Bi}} \eta_{\mathrm{Bi}}\right)\left(1-2 X_{\mathrm{Zn}} X_{\mathrm{Bi}} \frac{\Omega}{\mathrm{R} T}\right)
$$

Here, $X_{\mathrm{Zn}}$ and $X_{\mathrm{Bi}}$ are the mole fractions of $\mathrm{Zn}$ and $\mathrm{Bi}$, respectively; $\eta_{\mathrm{Zn}}$ and $\eta_{\mathrm{Bi}}$ are viscosities of pure metal $\mathrm{Zn}$ and $\mathrm{Bi}$, respectively, and $\Omega$ is the interaction parameter and is given by

$$
\Omega=X_{\mathrm{Zn}} H_{\mathrm{Zn}}^{0}+X_{\mathrm{Bi}} H_{\mathrm{Bi}}^{0}
$$

where $H_{\mathrm{Zn}}^{0}$ and $H_{\mathrm{Bi}}^{0}$ are the enthalpies of mixing of $\mathrm{Zn}$ and $\mathrm{Bi}$, respectively. The calculated value of the interdiffusion coefficient turns out to be $1.6 \times 10^{-9} \mathrm{~m}^{2} / \mathrm{s}$.

a. Case I: The $(0001)_{\mathrm{Zn}}$ plane as a growing plane

The crystallographic configuration for this case is such that the $S_{3}$ in Figure 7 represents a $(0001)_{Z n}$ growing plane and $S_{1}$ represents the $\{1010\}_{\mathrm{Zn}}-\mathrm{L}_{2}$ interface. Figure 8(a) plots the possible values of $\sigma_{s_{2}-l_{1}}$ and $\theta_{s}$ for different $\theta_{l}$ values in the range from -90 to $+90 \mathrm{deg}$, using Eqs. [7] to [9], which satisfy the mechanical-stability criterion. For $\theta_{l}=0$, the value of $\sigma_{s_{2}-l_{1}}$ is $0.18 \mathrm{~J} / \mathrm{m}^{2}$. This represents the condition for nonwetting of $L_{2}$. Figure 8(b) gives the parameter $\Gamma_{l} / \Gamma_{s}$ used by Derby and Favier as a function of $\theta_{l}$ for those cases which satisfy the mechanical-stability criterion. The estimation of 

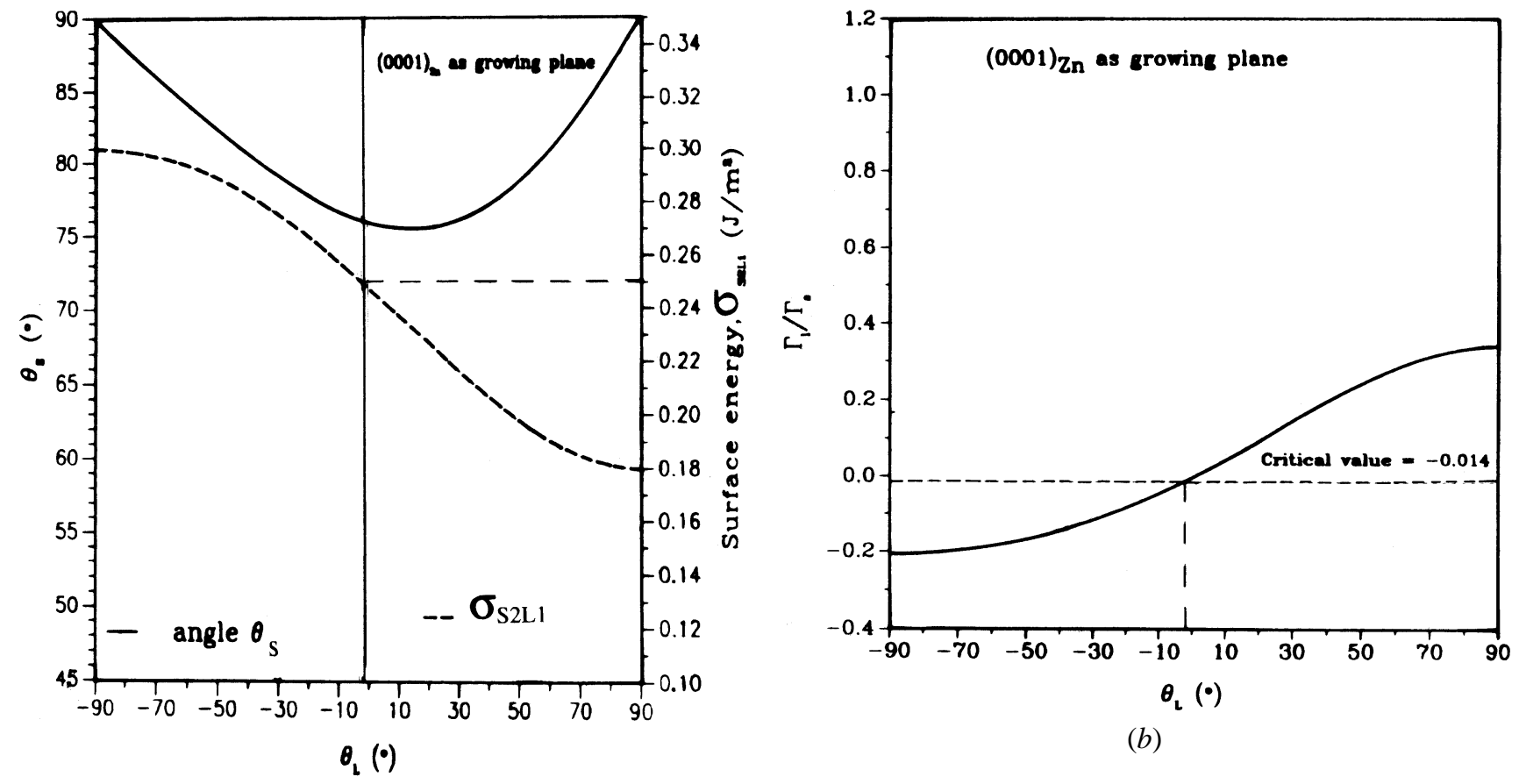

(a)

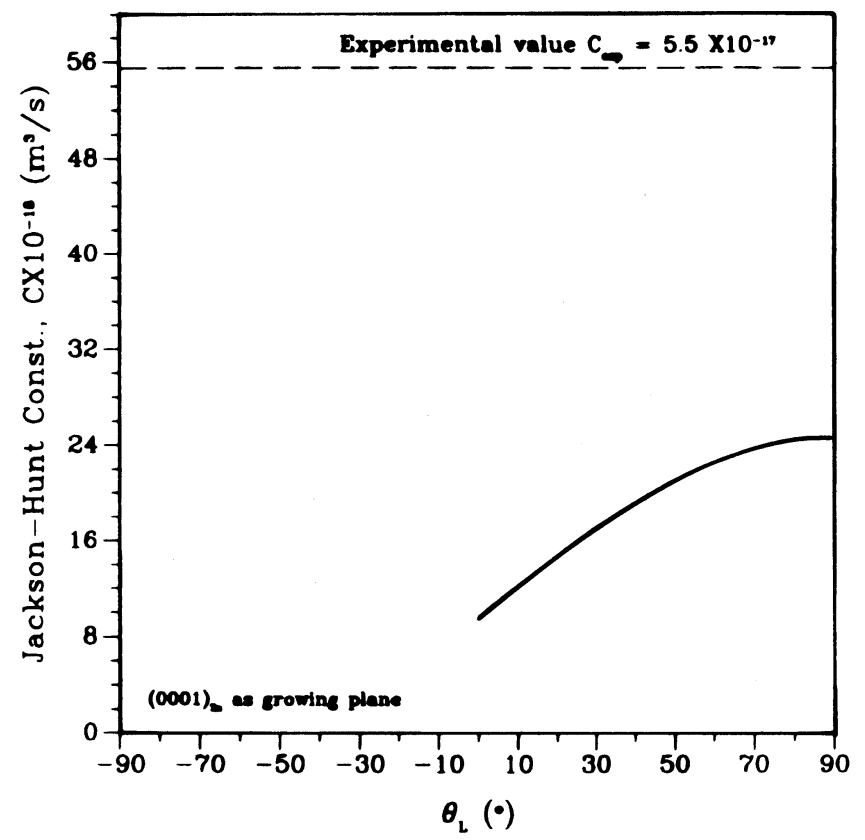

(c)

Fig. 8-(a) Possible combination of $\theta_{s}$ and $\sigma_{s_{2} l_{1}}$ when $\theta_{l}$ varies from -90 to +90 deg for $(0001)_{\mathrm{Zn}}$ plane taken as the growing plane facing the liquid $L_{1}$. (b) Derby's stability parameter as a function of $\theta_{l}$. The critical value for the stable monotectic growth is estimated as -0.014 . The $(0001)_{\mathrm{Zn}}$ plane is taken as the growing plane facing the liquid $L_{1}$. (c) Jackson-Hunt constant as a function of $\theta_{l}$ for $\mathrm{Zn}$-Bi alloy under the growth situation depicted in the (a).

the right-hand side of Eq. [10], with the help of the physical data given in Table III, yields the critical value of $\Gamma_{l} / \Gamma_{s}$ for stable growth to be -0.014 . This indicates that $\theta_{l}$ should have a minimum value of $-3 \mathrm{deg}$, which corresponds to the $\sigma_{s_{2}-l_{1}}$ value of $0.25 \mathrm{~J} / \mathrm{m}^{2}$. Thus, the range of surface energies of the $S_{2}-L_{1}$ interface which will yield stable growth will be from 0.18 to $0.25 \mathrm{~J} / \mathrm{m}^{2}$. Figure 8 (c) plots the JacksonHunt constant as a function of $\theta_{l}$ in this range. The experimentally observed value is also included as a dotted line, for comparison. We note that the experimental and calculated values have the same magnitudes, although the experimental value is 2 to 3 times more. Since $D$ is estimated in the present case, no further conclusion can be drawn. We also emphasize that experimentally observed aligned growth corresponds to the situation when $(0001) \mathrm{Zn}$ is the plane advancing into the liquid.

b. Case II: The $\{10 \overline{1} 0\}_{\mathrm{Zn}}$ plane as a growing plane

In Figure 7 , the crystallographic configuration of the growth interface $\left(S_{3}\right)$ is represented by the $\{10 \overline{1} 0\}_{\mathrm{Zn}}$ planes, 

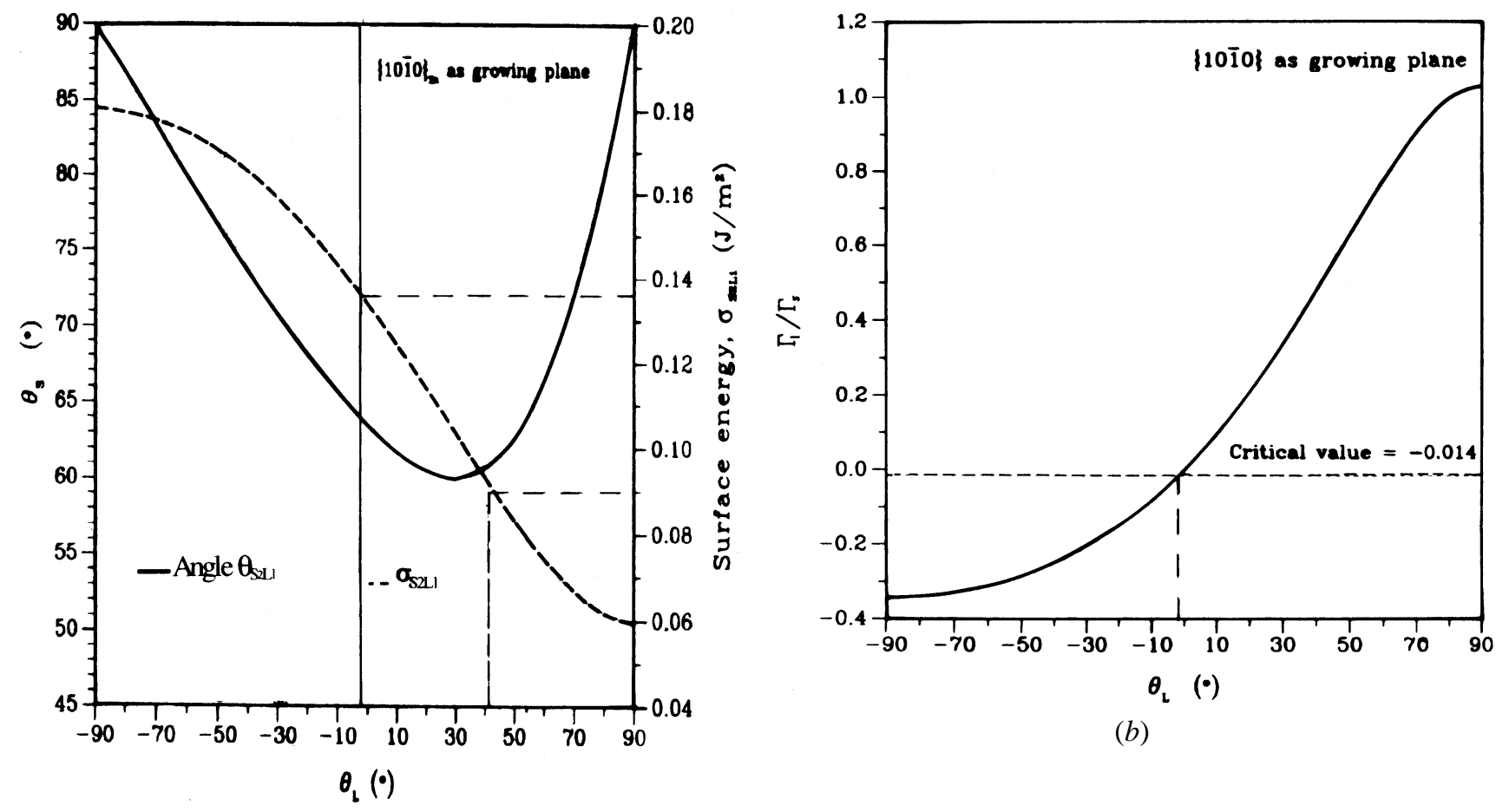

(b)

(a)

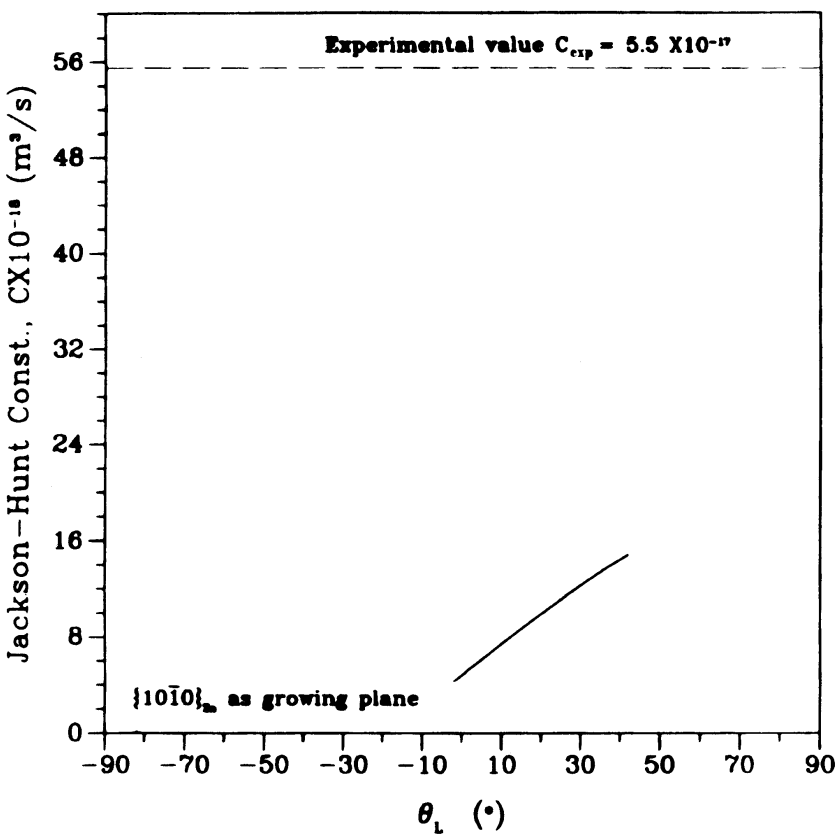

(c)

Fig. 9-(a) Possible combination of $\theta_{s}$ and $\sigma_{s_{2} l_{1}}$ when $\theta_{l}$ varies from -90 to +90 deg for $(10 \overline{10})_{\mathrm{Zn}}$ plane as the growing plane in the present case. (b) Derby's stability parameter as a function of $\theta_{l}$. The critical value for the stable monotectic growth is estimated as -0.014 . The $(10 \overline{10})_{\mathrm{Zn}}$ plane is assumed to be the growing plane. (c) Jackson-Hunt constant as a function of $\theta_{l}$ for $\mathrm{Zn}-\mathrm{Bi}$ alloy. The $(1010)_{\mathrm{Zn}}$ plane is the growing plane.

and $S_{1}$ is the $(0001)_{\mathrm{Zn}}$, plane Figure 9 (a) plots the possible value of $\theta_{s}$ and $\sigma_{s_{2}-l_{1}}$ as a function of $\theta_{l}$, which satisfies the mechanical-stability criterion. The minimum value of $\theta_{s}$ turns out to be $60 \mathrm{deg}$. This implies that $S_{2}$ will be one of those planes that makes an angle less than $30 \mathrm{deg}$ to the basal plane. This plane should have an energy more than or equal to $0.09 \mathrm{~J} / \mathrm{m}^{2}$, the energy of the basal plane which corresponds to the minimum possible energy. The corresponding $\theta_{l}$ value should be $42 \mathrm{deg}$ or less. Figure 9(b) gives
$\Gamma_{l} / \Gamma_{s}$, the Derby-Favier parameter, as a function of $\theta_{l}$. The critical value for stable growth from Eq. [10] is -0.014 , which now corresponds to a $\theta_{l}$ value of $-2 \mathrm{deg}$ and a $\sigma_{s_{2}-l_{1}}$ value of $0.14 \mathrm{~J} / \mathrm{m}^{2}$. Figure $9(\mathrm{c})$ plots the estimated Jackson-Hunt constant for each $\theta_{l}$ value within the $\theta_{l}$ window for stable coupled growth. The values are lower than in the previous case. Again, one can observe that at no combination of the surface energies and $\theta_{l}$ values is the estimated constant near the experimentally observed value. 
To summarize, parametric analysis of the coupled-growth behavior of a $\mathrm{Zn}-\mathrm{Bi}$ monotectic alloy, incorporating the mechanical stability of the interface, indicates that a window of surface energies exists for stable monotectic coupled growth. The experimentally observed Jackson-Hunt constant, which reflects the material properties, is of the same order as that estimated from the parametric analysis. However, more-accurate physical properties are required for direct comparison.

\section{CONCLUSIONS}

1. The coupled growth of a $\mathrm{Zn}-\mathrm{Bi}$ alloy at monotectic composition strongly depends on the crystallography of the growth interface. The aligned growth is associated with the [0001] growth direction of $\mathrm{Zn}$, reflecting the important role of surface-energy anisotropy on monotectic growth.

2 . The phase spacings for a given growth condition show a large amount of scatter. However, they can be fitted to a relation $\lambda^{2} V=c$, with the value of the constant being $5.5 \times$ $10^{-17} \mathrm{~m}^{3} / \mathrm{s}$

3. A parametric analysis of the coupled growth, incorporating the mechanical stability of the growth interface and the Derby-Favier criterion for stable monotectic growth obtained from the Jackson-Hunt theory, allows us to obtain all possible interface configurations for stable coupled growth.

\section{REFERENCES}

1. J.D. Livingstone and H.E. Cline: TMS-AIME, 1969, vol. 285, pp. 351-57.
2. B. Toloui, A.J. Macleod, and D.D. Double: Proc. Conf. In-Situ Composites IV, F.D. Lamkey, H.E. Cline, and M. McLean, eds., Elserver Science Publishing Co., Inc., Boston, MA, 1982, pp. 253-66.

3. R.N. Grugel and A. Hellawell: Metall. Trans. A, 1981, vol. 12A, pp. 669-81.

4. R.N. Grugel and A. Hellawell: Metall. Trans. A, 1982, vol. 13A, pp. 493-95.

5. B. Derby and J.J. Favier: Acta Metall., 1983, vol. 31, pp. 1123-30.

6. A. Kamio, S. Kumai, and H. Tezuka: Mater. Sci. Eng., 1991, vol. A146, pp. 105-21.

7. N.L. Frier, Y. Shiohara, and K.C. Russell: MRS, Intl. Mtg. Adv. Mater., 1989, vol. 4, pp. 47-52.

8. K.A. Jackson and J.D. Hunt: TMS-AIME, 1966, vol. 236, pp. 1129-41.

9. P. Magnin and R. Trivedi: Acta Metall. Mater, 1991, vol. 39, pp. 453-67.

10. G.A. Chadwick: Br. J. Appl. Phys., 1965, vol. 16, pp. 1095-97.

11. J.W. Cahn: Metall. Trans. A, 1979, vol. 10A, pp. 119-21.

12. B. Majumdar and K. Chattopadhyay: Metall. Mater. Trans. A, 1996, vol. 27A, pp. 2053-57.

13. W.A. Miller and G.A. Chadwick: Proc. R. Soc. A, 1969, vol. 312, pp. 257-76.

14. A. Passerone and N. Eustathopoulus: Acta Metall., 1982, vol. 30, pp. 1349-56.

15. R. Goswami and K. Chatttopadhyay: Phil. Mag. Lett., 1995, vol. 72, pp. $411-16$

16. W.A. Miller, G.J.C. Carpenter, and G.A. Chadwick: Phil. Mag., 1969, vol. 19, pp. 305-18.

17. F. Weinberg and B. Chalmers: Can. J. Phys., 1952, vol. 30, p. 488.

18. L. Battezzati and A.L. Greer: Acta Metall. Mater, 1989, vol. 37, pp. 1791-1802.

19. E.A. Moelwyn-Hughes: in Physical Chemistry, Pergamon, Oxford, United Kingdom, 1964, p. 793.

20. T.B. Massalski, ed., ASM, Metals Park, OH, Binary Alloy Phase Diagrams, 1986.

21. Smithells Metals Reference Book, 6th ed., E.A. Brandes, ed, Butterworth and Co. Ltd., England, 1983.

22. C. Kittel: Introduction to Solid State Physics, 5th ed., Wiley Eastern Limited, New Delhi, 1985, p. 100.

23. A.K. Nessen, F.R. de Boer, R. Boom, P.F. de Chatel, W.C.M. Mattena, and A.R. Miedema: Cal. Phad., 1983, vol. 7, pp. 51-70. 